\title{
Análise diagnóstica do atendimento pré-hospitalar para acidentes e violências contra idosos em Curitiba (PR, Brasil)
}

\author{
Situational analysis of the pre-hospital health services for \\ attending accidents and violence against the elderly in Curitiba (PR, \\ Brazil)
}

Ana Lucia Schaefer Ferreira de M ello ${ }^{1}$

Samuel Jorge M oysés ${ }^{2}$

\footnotetext{
${ }^{1}$ UniversidadeFederal de SantaCatarina. Campus Reitor João David Ferreira Lima, Trindade. 88040-970 Florianópolis SC.

alfm@terra.com.br

2 Pontifícia Universidade

Católica do Paraná
}

Abstract This study is a situational analysis of the health care services for attending accidents and violence, in Curitiba, focusing the general conditions of infrastructure, planning and support at the pre-hospital assistancelevel, considering mobile and fixed emergency services dedicated to the victimized elderly. Positive points were evidenced as well as gaps and needs to meet the national guidelines. The investigation integrated quantitative and qualitative approaches and it was carried out on the grounds of the triangulation of methods. It is concluded that on the theme of accidents and violence against the elderly still there is room for important improvements in the actions developed by the researched services: (1) preventive actions are not part of the routine of the services; (2) most of the services does not develop specific services, addressed to the peculiar demands of the elderly; (3) the interviewees' experience reveals difficulties for obtaining hospital beds, either for referral or transfer/admission of patients. Facing the issue of accidents and violence against the elderly in Curitiba requires considering the organization of data, flows, training of professionals and planning in the development of prevention programs, attendance and rehabilitation to the elderly.

Key words Elderly, Elder abuse, Violence, H ealth services for the elderly
Resumo 0 estudo compõe uma análise situacional dos serviços de atenção a acidentes e violências, em Curitiba, focalizando as condições gerais de infraestrutura, planejamento e apoio no nível de atenção pré hospitalar, considerando os serviços préhospitalares móveis e fixos, dirigidos ao atendimento do idoso vitimizado. Foram evidenciados pontos positi vos, lacunas e necessidades de adequação para atender às diretrizes nacionais. A investigação integrou abordagens quantitativas $e$ qualitativas e se pautou nos princípios da triangulação de métodos. Conclui-se que o tema dos acidentes e violência contra idosos comporta importantes melhorias nas ações desenvolvidas pel os serviços pesquisados: (1) ações preventivas não fazem parte da rotina dos serviços; (2) a maioria dos serviços não desenvolve atendimentos específicos, direcionados às demandas particulares dos idosos; (3) a experiência dos entrevistados revela dificuldades de obtenção de lei tos hospitalares, para encaminhamento ou transferência de pacientes idosos. 0 enfrentamento das questões relativas aos acidentes e violências contra idosos em Curitiba impõe considerar a organização de dados, fluxos, capacitação dos profissionais e planejamento no desenvolvimento de programas de prevenção, assistência e reabilitação aos idosos vitimizados. Palavras-chave Idoso, M aus-tratosao idoso, Violência, Serviços de saúde para idosos 
Introdução

Este estudo descreve como estão estruturados e como operam, no município de Curitiba (PR), os serviços de saúde para atendimento pré-hospitalar dos agravos sofridos por sua população idosa, especificamenteos provocados por acidentes e violências. Esses dois temas, violência e acidentes, abordados em conjunto e do ponto de vista geriátrico e gerontológico, carecem de conhecimento aprofundado, pois a violência contra idosos e mesmo sua exposição aumentada para acidentes só recentemente foram incorporadas à agenda política do setor saúde. Tais problemas, em razão dos agravos acarretados para a população idosa em sua saúde física e mental, já têm merecido a atenção em outros países, eno Brasil são ainda questões pouco estudadas ${ }^{1,2}$.

Além de observar estatísticas de mortes einternações por causas violentas ${ }^{3}$, é necessário enfatizar a existência de muitos eventos não fatais como agressões físicas e psicológicas que revelam abusos e negligências a que estão expostos os idosos no contexto familiar, na comunidade e nas instituições ${ }^{1,4}$.

No caso brasileiro, as violências contra pessoas com 60 anos ou mais se expressam em tradicionais formas de discriminação. Por parte do Estado, o idoso sofre uma enorme omissão quanto a políticas e programas de proteção específicos. No âmbito das instituições de assistência social e saúde, são frequentes as denúncias de maus-tratos e negligências. Além disso, há importantes situações de abusos e negligências no interior dos próprios lares.

Asviolências contra idosostambém são denominadas maus-tratos e abusos. Esse conjunto de termos compreende abusos físicos, psicológicose sexuais, e ainda três formas muito presentes em nível tanto doméstico quanto institucional no Brasil: 0 abandono, negligências eos abusosfinanceiros. Delasadvêm, frequentemente, lesões etraumas físicos, emocionais e sociais para a pessoa ${ }^{1}$.

Os idosos no Brasil são portadores de pelo menos uma doença crônica e utilizam um medicamento regularmente. Um em cada três idosos pode apresentar sintomas psiquiátricos, e seus cuidadores informais sofrem um impacto decorrente desse papel. Os serviços de saúde disponíveis não são suficientes para as necessidades de cuidado dessas pessoas. As síndromes depressivas e demenciais são os problemas mentais mais prevalentes na população idosa. Estudos de prevalência específicos dessas síndromes nos idosos da comunidade também são escassos no país ${ }^{5}$.
A demanda crescente de serviços para atendimento de lesões e traumas provocados por esse fenômeno na população idosa vem exigindo novas habilidades, equipamentos e organização do sistema de saúde. Dessa forma, o M inistério da Saúde (M S) lançou em 2001 a Política Nacional de Redução da M orbimortalidade por Acidentes eViolências, colocando o tema prioritariamente na agenda do setor saúde 1 .

Pesquisa realizada pelo Centro Latino-Americano de Estudos sobre Violência e Saúde Jorge Careli da Fundação Oswaldo Cruz (Claves/Fiocruz) ${ }^{6}$ caracterizou serviços queaten dem vítimas de acidentes e violências em capitais das cinco regiões brasilei ras com altos índices deviolências eacidentes na época: Recife, Rio de Janeiro, $\mathrm{Ma-}$ naus, Curitiba e Brasília. Na cidade de Curitiba, foram identificados 18 serviços que atendem vítimas de acidentes eviolências, sendo seteunidades de pré-hospitalar, seis hospitais, três de reabilitação e duas de organizações não governamentais (ONGs). A ampla maioria (94,1\%) desses serviços aten de a crianças e adolescentes. Curitiba apresentou, juntamente com M anaus, as maiores proporções de serviços que atendiam homens, mulheres e idosos (83,3\%, 83,3\% e $72,2 \%$, respectivamente). As principais ações de atendimento observadas para o conjunto dos serviços foram o suporte social $(61,1 \%), 0$ atendimento ambulatorial $(61,1 \%)$ e o hospitalar (55,6\%). Em geral, observou-se que as ações de prevenção não fazem parte do cotidiano da totalidade dos serviços de Curitiba.

O presenteestudo compõeuma análise situacional dos serviços de atenção a acidentes e violências no município de Curitiba considerando as condições gerais de infraestrutura, de planejamento e de apoio no nível de atenção pré-hospitalar, móvel e fixa, dirigida ao atendimento do idoso vitimizado, evidenciando pontos positivos, lacunas eas necessidades deadequação para atender às diretrizes nacionais.

\section{Método}

A investigação integrou abordagens quantitativas e qualitativas e se pautou nos princípios da triangulação de métodos ${ }^{7}$. A pesquisa teve sua coordenação geral sediada no Claves, Rio de Janeiro, no âmbito do projeto Análise Diagnóstica de Sistemas Locais de Saúde para Atender aos Agravos Provocados por Acidentes e Violências aos Idosos. Todos os passos da pesquisa foram discutidos entre os coordenadores do Claves e 
dos cinco municípios participantes, propiciando um trabalho coletivo e de aprimoramento da qualificação dos pesquisadores e dos instrumentos de coleta de dados. 0 processo investigativo iniciou-secom o mapeamento dasiniciativas existentes de atenção a idosos vítimas de acidentes e violências em Curitiba.

A primeira fase da pesquisa foi realizada com gestores e profissionais, informantes-chave, envolvidos em ações voltadas para o atendimento dos agravos causados por acidentes e violências contra idosos. Foram entrevistados quatro gestores: profissional do serviço municipal de saúde mental, profissional do serviço de urgência e emergência, profissional do serviço municipal integrado de saúde e profissional da Fundação de Ação Social. As entrevistas seguiram um roteiro semiestruturado, sendo gravadas e, poste riormente, transcritas. Foram levantados os pontos mais relevantes para proceder ao diagnóstico situacional e identificados também os serviços de saúde e instituições a serem convidados para participar da segunda fase da pesquisa, considerando a capacidade de cobertura, relevância e integração com o Sistema Ú nico deSaúde(SUS).

Em seguida foi aplicado um questionário semiestruturado a profissionais dos serviços que respondiam por programas de atendimento aos idosos em situação de acidentes e violências, objetivando caracterizar as instituições e descrever suas atividades. Foram pré-identificados 28 serviços/programas, sendo 18 na área clínica e dez em saúde mental, em três níveis de atuação (pré hospitalar, hospitalar e reabilitação). Na área clínica foram nove pré hospitalares, seis hospitalares e três de reabilitação. Especificamente na área da saúde mental, foram seis pré hospitalares equatro hospitalares. Responderam ao questionário na segunda fase da pesquisa, no nível pré-hospitalar, oito instituições na área clínica e seis na área de saúde mental, constituindo estes 0 objeto deste artigo.

Os 14 serviços pesquisados foram classificados conformeo tipo deassistência prestada, considerando: (1) Serviço pré-hospitalar móvel: Sistema de Atendimento Municipal às Urgências Serviço de Atendimento M óvel de Urgência (Samu)/Serviço Integrado de Atendimento ao Trauma em Emergência (Siate); e(2) Serviço préhospitalar fixo: Centros M unicipais de Urgências M édicas (CM U M) e Unidade de Saúde especializada no Atendimento ao Idoso. Ainda na segunda fase, buscou-se caracterizar 0 atendimento dosserviçosidentificados no mapeamento. Foi aplicado um segundo questionário semiestrutu- rado com foco no cumprimento das diretrizes de estruturação, sistematização, ampliação e consolidação do atendimento pré hospitalar às vítimas de acidentes e violências em consonância com a Política Nacional. 0 instrumento incorporou questões referentes à estrutura dos serviços (recursos humanos, estrutura física, equipamentos), à organização e ao registro de dados. Complementando os dados dos questionários, na segunda fase da pesquisa também foram feitas 14 entrevistas com profissionais, entre os quais: médico psiquiatra e ortopedista, assistente social, psicóloga e coordenador de Centros de Atenção Psicossocial (CAPs), coordenador de hospital psiquiátrico, gerontólogo, fisioterapeuta, gestor, socorrista e médico do Samu/Siate, profissionais de hospital deemergência, deserviço de reabilitação e de centro de referência no atendimento ao idoso. Do mesmo modo, as entrevistas seguiram um roteiro semiestruturado, sendo gravadas e transcritas.

O estudo teve aprovação do Comitê de Ética em Pesquisa da Escola Nacional de Saúde Pública Sergio Arouca, da Fundação O swaldo Cruz (CEP/Ensp), sob o Parecer $n^{\circ} 85 / 06$. Todos os entrevistadosforam previamenteesclarecidos dos objetivos e método da pesquisa, manifestando seu consentimento por meio da assinatura do Termo de Consentimento Livree Esclarecido.

\section{Resultados ediscussão}

Caracterização da rede de serviços de saúde do SUS em Curitiba

A rede de atenção assistencial do SUS deCuritiba é composta por um conjunto de serviços próprios e conveniados para cobrir uma população total estimada, em 2008, de 1.828.092 habitantes. Estima-se que $70 \%$ dos curitibanos, além de pessoas não residentes em Curitiba, utilizam essa rede.

Em 2009, a rede própria municipal estava organizada em nove Distritos Sanitários, sendo composta por 134 Equipamentos de Saúde: 51 Unidades Básicas de Saúde (UBS); 53 U BS com Estratégia Saúde da Família (ESF); oito Centros Municipais de Urgências M édicas (CMUM ); 11 Unidades Complexas; nove Centros de Atenção Psicossocial (CAPs); um Hospital Municipal; e um Laboratório Municipal, três ambulatórios especializados nas Escolas de Educação Especial e oito Centros M unicipais de Atendimento Especializado (CM AES). Com o aumento da expec- 
tativa de vida de sua população, haverá necessidade deseincrementarem serviços e ações voltados às patologias próprias do envelhecimento.

Em 2008, no nível da atenção básica de saúde foram realizados 2.596 .195 consultas médicas básicas, 7.563.153 ações bási cas deenfermagem e ProgramaAgente Comunitário de Saúde (PACS) e 3.094.210 ações básicas de odontologia, totalizando 13.527.244 procedimentos. Foram atendidas 612.986 pessoas pela Estratégia Saúde da Família (cobertura de 33,7\%) e realizados 2.217.966 exames de patologia clínica no Laboratório Municipal. 0 sistema deurgência/emergência deCuritiba atendeu 241.847 ligações/ocorrências, prestando 93.263 atendimentos com Unidades M óvei ${ }^{8}$.

Caracterização do atendimento pré-hospitalar para acidentes e violências contra idosos

0 atendimento préhospitalar móvel

Em Curitiba, desde 1990 o atendimento ao trauma é feito pelo Serviço I ntegrado de Atendimento ao Trauma em Emergência (Siate), gerenciado pelo Corpo de Bombeiros. A implantação do Serviço de Atendimento M óvel de Urgência (Samu) em Curitiba ocorreu a partir dejulho de 2004, como resultado do esforço feito pelo município para implementar a assistência pré-hospitalar no âmbito do SUS. Atende quadros agudos de natureza clínica, traumática ou psiquiátrica que ocorrem fora do ambiente hospitalar. Com a implantação do Samu foram incorporados os serviços do Siate, respeitando-se a autonomia de cada instituição parceira.

O Samu faz parte do Sistema de Atendimento Municipal às Urgências, queécomposto pelos CM UM ; pelas ambulâncias do Siate e do Samu; pela Central de Regulação M édica e por unidades de emergência dos hospitais de referência (para adulto/idoso) da cidade. Um dos principais focos do Samu éa organização de uma rede de atenção integral para as urgências, regulando o fluxo dos pacientes da atenção básica até a alta complexidade. A estrutura do Samu/Siate para o atendimento pré-hospitalar móvel existente é superior aos parâmetros preconizados pelo $\mathrm{M} \mathrm{i-}$ nistério da Saúde; mesmo assim, o dimensionamento da frota assistencial é um complicador, por não haver reserva técnica.

$\mathrm{H}$ oje, o Siate atende de $80 \%$ a $85 \%$ das ocorrências, com vítimas leves ou vítimas graves sem risco de morte. Os casos mais graves giram em torno de $10 \%$ a $15 \%$; são vítimas com risco de morte, em pior estado. N esses casos, um médico acompanha a equipe de resgate.
O Samu em Curitiba foi o segundo do país, ajustado ao modelo nacional, atendendo a todos os tipos de emergência, não só às clínicas. Também atendea situações detraumas, em apoio ao Siate ou, às vezes, a uma chamada decorrente deacidente. Tanto o Siate como o Samu atendem a casos clínicos fora da capital paranaense, em especial os trinta municípios da região metropolitana de Curitiba.

Embora separados fisicamente em suas sedes, uma linha restrita possi bilita interagirem os dois serviços. Recebem a ligação e coletam as informações: idade, endereço, caso, entre outras, depois repassam para o médico, que faz a triagem e decide 0 enquadramento. Existem, também, os radioperadores, que controlam a fonte da informação. Os atendimentos do Siate giram em torno de2.000 por mês, edo Samu entre 3.500 e 4.000 ocorrências por mês.

Não há um plano específico de atendimento ao idoso, poisesteingressa no fluxo normal como qualquer outra faixa etária. Os casos de idosos vítimas de violência só são descobertos quando a violência extrapola os limites do domicílio e então é necessário o socorro. N esses casos, 0 atendimento feito pelo Siate é visto como mais qualificado pelo fato de ter facilidade em ações policiais. Quando são identificados casos de agressão, a polícia é acionada e também acompanha o resgate. 0 Siate geralmente aciona a Polícia M ilitar, e o Samu, a Guarda M unicipal.

Com relação às dificuldades no atendimento ao idoso, foi relatado o crescimento dessa demanda (a população acima de 60 anos perfaz 8,5\% da população total) não acompanhado pela oferta de serviços especializados, como serviço de ortopedia que atenda a fratura de colo de fêmur. Reporta-se que, em razão de patologias crônicas, 0 idoso é mais suscetível a eventos externos (acidentes) e problemas deles derivados. Essa peculiaridade faz com que o idoso apresente comorbidades quemuitas vezes podem fazer com queuma cirurgia de bom prognóstico leve a um óbito, ou se apresentem complicações pós-operatórias.

O modelo de pagamentos do SUS, considerado defasado, também sofreu fortes críticas e pode influenciar negativamente 0 atendimento ao idoso, principalmente o encaminhamento ao nível hospitalar. Dificilmentese consegue prestação de serviço que não em hospital público. Faltam leitos, e muitos estão desativados.

Em relação à capacidade de resposta, o Siate é considerado muito mais rápido. 0 Samu se obriga a cumprir um protocolo, modelo nacional, e demora mais no atendimento. Das entrevistas recolhe-se aindicação da necessidade de os 
serviços pré-hospitalares móveis dedicarem uma atenção personalizada ao paciente idoso, o que implica a formação e o treinamento dos profissionais atendentes etambém adaptações nos equipamentos e materiais. A condição idosa do paciente atendido tem peculiaridades que necessitam ser tomadas em conta por esse rel evante serviço.

Atendimento pré-hospitalar fixo: os Centros M unicipais de U rgências Médicas

OsCMUM fazem parteda redemunicipal de saúde e integram o sistema de atendimento às urgências eemergências, como unidades deatendimento pré-hospitalar fixo. Realizam atendimento de emergência - procedimentos médicos e de enfermagem - para estabilização dos casos leves no próprio serviço ou encaminhamento aos hospitais de referência, se necessário. A tendem a população de Curitiba e de outros municípios vizinhos.

Os CMUM não dispõem de serviços próprios de radiologia e laboratório de patologia clínica; esses serviços são realizados pelos hospitais de retaguarda de maneira ininterrupta. Os Centros Municipais deU rgências M édicas acionam a central de regulação apenas quando a capacidade de atendimento do hospital de retaguarda tem a sua capacidade de atendimento ultrapassada. Há um fluxo dereferênciaecontrarreferência com asUBS.

As dificuldades apontadas na rotina de atendimento geral dos CMUM são: o dimensionamento insuficiente da equipe da estrutura física ante a demanda diária e a falta de leitos nos hospitais de referência para encaminhamento dos pacientes com problemas clínicos, resultando na permanência desses pacientes, aguardando vaga, por mais tempo do que o necessário. Esses problemas não se aplicam ao atendimento de urgência e emergência por motivos externos, porqueos CM U M dispõem de médicos emergencistas preparados para atender com prioridade os casos de baixa complexidade e fazer encaminhamento direto das vítimas de maior complexidade aos hospitais de retaguarda.

Os idosos ocupam $11,5 \%$ a $15,7 \%$ do total de atendimentos prestados nos $\mathrm{CMUM}^{9}$ Porém, todos os centros revelaram dificuldade para informar o número de atendimentos relacionados a acidentes e violências, pois o sistema informatizado não comportava programação para emitir relatórios com essa especificidade. 0 habitual é a emissão de relatórios gerenciais de apoio às atividades administrativas.

Os CMUM possuem as dependências necessárias para um bom atendimento, como salas de observação (masculina, femininae edediátrica), sala desutura ecurativos, sala de reanimação eestabilização, entreoutras, além de contar com a maioria dos equipamentos e medicamentos preconizados. A capacidade instalada, apesar de ser a necessária, está saturada pela demanda. Os componentes da estrutura física dos CM U M estão voltados para o serviço ambulatorial médico, e 0 apoio diagnóstico é prestado em outras unidades. Os centros pesquisados não contemplam atendimento odontológico, psicológico, radiológico, laboratório de patologia ou sala de gesso.

Geralmente, o Samu faz o primeiro atendimento de um idoso na residência, no trabalho ou na rua e desloca-o até um CM U M. Daí, caso seja necessário transferi-lo para a rede hospitalar, a situação se complica, pois a oferta de leitos sofre restrições comparativamente a outras faixas etárias. É provável que essas restrições adicionais reflitam o comportamento econômico de gestores hospitalares, cientes de que os idosos têm tempo de internação mais longo, inclusive em UTI. Esse grave complicador no fluxo de encaminhamento de idosos não é percebido nos casos de demanda por trauma. Entretanto, especialmente em agravos clínicos, normalmente os CM U M estão repletos de idosos com situações de AVC ou diabetes, aguardando vaga hospitalar. Há insuficiência de oferta para cobrir as necessidades, e os serviços de urgência/emergência dos hospitais de referência também seencontram superlotados.

Todas as unidades/serviços de atendimento pré hospitalar em Curitiba se articulam com a redehospitalar por meio deuma central deregulação; possuem transporte próprio para o deslocamento dos pacientes e praticam um mecanismo de referência e contrarreferência para os casos de internação, sendo que os CMUM reportam atuar integrados com as equipes da Estratégia Saúde da Família, visando à manutenção da capacidade funcional do idoso. Exceto no único serviço especial izado de atenção a idososa seguir descrito, nas demais unidades/serviços do atendimento pré-hospitalar não são efetuadas abordagens preventivas de avaliação e testes de triagem no campo dos distúrbios cognitivos, nutrição, visão, audição, depressão, mobilidade, comprometimento da funcionalidade e isolamento social do idoso.

Atendimento pré-hospitalar fixo: a Unidade de Atenção ao I doso O uvidor Pardinho

A UnidadedeAten ção ao Idoso Ouvidor Pardinho localiza-seno Centro deCuritiba, ondehá 
maior concentração de idosos, efunciona como U BS. Seus serviços são preponderantementevoltados às pessoas idosas. É também unidade de referência para tratamento de doenças como Parkinson e Alzheimer. Oferece consultas médicas nas seguintes especialidades: gi necologia, geriatria, clínica médica, além de atendimento odontológico e de enfermagem. Também oferece serviços de inalação, vacinas, curativos e marcação de consultas especializadas. A unidade conta com o apoio parceiro de uma universidade privada nas áreas de nutrição, fisioterapia, fonoaudiologia, enfermagem, terapia ocupacional, psicologia e odontologia. Ainda são desenvolvidas na unidade atividades de educação física em parceria com a Secretaria M unicipal deEsportee Lazer (SMEL) e atividades educativas e lúdicas com a Fundação de Ação Social (FAS), dirigidas à população ali atendida.

Aspectos relevantes relacionados com o atendimento prestado pela Unidade Ouvidor Pardinho são apontados pelos entrevistados. Eles reportam queosidosos têm muita dificuldade para se deslocarem até a unidade e aí falarem sobre suas falências e debilidades, o que provoca importante retardo no início do tratamento. Por sua vez, a família costuma sentir-se culpada por ter estado de algum modo afastada do dia a dia do idoso. Particularmente, na questão dos maustratos o maior problema é "furar o bloqueio" da pessoa idosa para que ela exponha as causas e os agentes dos maus-tratos. Os idosos têm muita dificuldade de dar a público tais situações vergonhosas e humilhantes, porque, em geral, um familiar é o agressor. Em contraste, também dificulta a ação do serviço de saúde o fato de que muitos idosos hoje vivem sós, sem referência familiar. O s entrevistados apontam a falta de uma rede unificada de proteção ao idoso ea fragilidade dos procedimentos para a notificação de maus-tratos. Ademais, muitos idosos não procuram as instituições que deveriam defendêlos, por receio de piorar relacionamentos, inclusive com familiares no domićlio.

Em geral, o sistema de proteção jurídica ao idoso é moroso e distante. Aponta-se a falta de um órgão mais resolutivo. A Unidade Ouvidor Pardinho sublinha um sentimento de impotência em face dos limites do seu campo de atuação e possibilidades: nas situações com implicações policiais e jurídicas, a unidade apenas faz os encaminhamentos possíveis.

Os entrevistados também reportam dificuldades no processo de encaminhamento a um CM UM ou então para internação hospitalar do idoso, após o primeiro atendimento dado no setor de emergência (observação) da Ouvidor Pardinho. $\mathrm{Na}$ esfera hospitalar, tais restrições teriam como origem: Ionga permanência, uso de múltiplas medicações, necessidade de cuidados mais diversificados e frequentes ${ }^{10}$, ser portador de várias patologias, ter acompanhamento necessário de nutricionista, enfermeiro, fisioterapeuta ou psicólogo, no sentido de abordar principalmente a questão da dependência. Em suma, se a condição idosa já implica restrições, uma situação de acidente aprofunda a dificuldade, que será agravada ainda mais caso se trate de uma pessoa idosa portadora de transtorno mental. Paradoxalmente, o idoso deve apresentar uma situação de saúde muito fragilizada para obter mais rapidamente a internação.

0 atendimento de idosos com transtorno mental tem suas peculiaridades. 0 idoso apresenta dificuldadeem aceitar sua condição, a referência para tratamento e a medicação prescrita. Não raro o idoso, que pode ser muito beneficiado, recebeo medicamento gratuitamentee retorna sem ter feito uso regular. Casos de depressão, por não ter havido procura de ajuda em fase oportuna, tornam-se graves e mais difíceis de terem a recuperação proporcionada; eis que 0 idoso já apresenta muita dificuldade para sair de casa. Em relação aos idosos com transtorno psiquiátrico, psicose e esquizofrenia, a família costuma desenvolver sentimentos de rejeição, porque não entende que se trata de um transtorno, confundindo com o temperamento da pessoa.

Os programas de Parkinson e Alzheimer incluem reuniões mensais, com a participação dos familiares, constituindo momentos de trocas de experiências entre cuidadores. Observa-sequehá cuidadores que não se cuidam convenientemente. A unidade está consciente de que deve al ertar o cuidador para estar atento a sua saúde e ao convívio social. Além disso, aconselha o cuidador a dividir as tarefas com a família, se possível, pois a situação do idoso tende a ser de declínio. Soma-se o fato de a pessoa idosa com transtorno mental geralmente apresentar comorbidades crônicas e fazer uso de várias medicações. Por ser idosa, os efeitos colaterais são mais acentuados ${ }^{11}$ e mai or é o risco de ela sofrer quedas, fraturas ou acidentes em casa ou na rua.

A administração da medicação do idoso também é considerada uma questão difícil. 0 serviço não sabe com precisão quais as condições do idoso para dar conta da sua medicação (horário, dosagem, interação medicamentosa). É muito comum se encontrarem idosos intoxicados pelas 
medicações, por falta de pessoa apta ou dedicada ao controle.

Em geral, os idosos são trazidos à unidade especializada O uvidor Pardinho por familiares ou por vizinhos. 0 membro dafamília mais frequente éa filha. A situação étida como complexa, pois mesmo parentes com as melhores intenções têm seus compromissos pessoais e profissionais, agravados no meio urbano de grandes cidades. A presença de um idoso dependente no domicílio, demandando cuidados de saúde com mais intensidade, faz com que pessoas deixem de trabalhar ou trabal hem menos para poderem se dedicar ao seu familiar idoso, ou dispondo de renda comprometam parte do orçamento para contratar cuidador, atividade que tende a demandar maise mais pessoas dedicadas e qualificadas.

A ponta-se também para as questões advindas de conflito intergeracional. É comum, nos dias de hoje, a convivência próxima de idosos com crianças e adolescentes, e estes, com sua impaciência característica, nem sempreestão preparados para lidar com o idoso. Também ocorre, comumente, de idosos cuidarem de idosos. Os cuidadores nessas situações também precisam cuidar de sua saúde, o que gera um conflito de prioridades.

A unidade faz atendimento domiciliar. São acompanhadas sessenta famílias com idosos acamados. 0 acompanhamento domiciliar contempla atendimento com auxiliar de enfermagem, fisioterapia, nutricionista, coleta dematerial para exame em laboratório.

A Unidade Ouvidor Pardinho comumente atendeidosos vítimas de acidentes domésticos. $\mathrm{A}$ infraestrutura do domicílio sem adaptações favorecea ocorrência dequedas e outros acidentes. Outra categoria frequente de acidenteéo atropelamento por veículo motor.

$\mathrm{Na}$ questão das vítimas de violência domiciliar, os envolvidos, quase sempre, são pessoas de contato mais próximo: ou éfamiliar ou éo cuidador. Geralmente, quem faz a chamada telefônica solicitando socorro nos casos de violência doméstica évizinho. Às vezes, porém, mais raro, algum familiar considerado "neutro" entra em contato. A denúncia na maioria dos casos parte de al guém que não é membro da família, que não pertence ao núcleo familiar. Todavia, quando a violência é praticada por cuidador, a família denuncia.

A Unidade Ouvidor Pardinho recebe queixas formais do M inistério Público e então procede à busca do caso na comunidade, por meio dos seus profissionais de enfermagem e psicologia. Por ser aúnicaunidadeem Curitiba especializada na aten- ção ao idoso, recebe denúncias de todo o município. N esses casos, é feita a visita, elaborado um relatório do quadro encontrado e encaminhada uma cópia também para a unidade de referência do domicílio do idoso, para que aquela unidade de saúde se comprometa a acompanhar mais amiúde a pessoa.

Os idosos vitimizados são recomendados a demandar os serviços da procuradoria de defesa dos direitos da pessoa idosa, bem como orientados sobre os direitos expressos pelo Estatuto do Idoso. Os casos são sempre acompanhados por uma psicóloga, que realiza visitas domiciliares. É elaborado um relatório detal hado e enviado ao M inistério Público. A grande maioria dosidosos vitimizados retorna à unidade para que haja continuidade nas visitas domiciliares e acompanhamento do caso. Em algumas situações, o idoso, juntamente com a família e a orientação do serviço, decide viver em uma instituição de longa permanência.

A Unidade O uvidor Pardinho interage com a Fundação de Ação Social por meio do serviço SOS Idoso. 0 trabalho é avaliado como muito bom. A unidade tem um profissional psicólogo preparado para atender todas as visitas, especialmente de identificação de violências, denúncias do M inistério Público e queixas por telefone.

A sistematização do atendimento

préhospitalar às vítimas de acidentes

e violências em Curitiba

Dados informados relativos ao ano de 2006 dão conta de que os CMUM pesquisados efetuaram 85.014 atendimentos a idosos, correspondendo a $22,5 \%$ do total de atendimentos registrados. Outros 124.000 atendimentos a idosos ocorreram em ambulatório especializado. Não há dado disponível que permita indicar o número de agravos por acidentes e violência contra esses idosos. Os dois serviços pré hospitalares móveis informam $490(0,86 \%)$ atendimentos decorrentes de violência contra idosos e 1.551 $(2,72 \%)$ em consequência de acidentes com idosos, num total de 57.108 atendimentos.

Deum modo geral, as unidades/serviços também revelam ter melhorado a integração com os serviços de segurança, judiciários e de ação social para os quais encaminham e dos quais também recebem idosos. É pouco presente a integração com as áreas de educação, lazer, esporte, turismo e trabalho.

Não há nas unidades/serviços pré-hospitalares qualquer atividade de suporte ou acompanhamento com relação à pessoa do(s) agres- 
sor(es) que vitimam idosos, nem adequado e suficientesuporteàfamília da vítima è̀s equipes de atendimento. Os dados informados permitem inferir que são poucas e até inexistentes em al gumas unidades/serviços as ações de identificação e prevenção de acidentes/violência de idosos. Em relação aos casos atendidos em consequência de violência, só uma unidade reportou que procura investigar as causas. Destaca-se que foi relatada apenas por um serviço a capacitação de profissionais para identificação de casos de violência e por dois serviços a capacitação para 0 atendimento e registro de dados.

Em geral não há protocolo para o atendimento do idoso vitimado, à exceção de um serviço móvel e dois CM U M que informaram adotar protocolo clínico. Três serviços relataram efetuar a notificação por telefone. M esmo aqueles quemantêm registros não costumam efetuar análise sistemática dos dados ena mesma linha não os têm presentes parafins de planejamento das ações, exceção feita aos serviços móveis que informaram analisar os registros, utilizá-los em sua programação, enviálos à vigilância epidemiológica ereceberem dados de seu atendimento consolidado.

As informações coletadas mostram que as notificações são dirigidas a organismos diversos como Polícia, M inistério Público, Secretaria Municipal ou Estadual de Saúde ou ainda Secretaria de Assistência Social. Não se dá conta da existência de uma unidade centralizadora das informações. Curitiba mantém um serviço SOS Idoso, vinculado à Central de Resgate Social.

Os respondentes indicam queo conhecimento das políticas públicas sobre a pessoa idosa, em particular a Política Nacional de Redução da M orbimortalidade por Acidentes e Violência (PNRMA), é ainda superficial, e o Estatuto do Idoso, mais difundido, foi reportado como lido por cinco deles. A PNRMA não é do conhecimento de alguns serviços/unidades.

Percebe-se que a demanda espontânea por serviços de saúde, no nível pré-hospitalar, por idosos vítimas de acidentes e violência ainda é pequena, quando comparada com a procura decorrente de outras causas pelas pessoas dessa faixa etária ${ }^{12}$; considera-se que a tendência é de aumento da ocorrência de casos. Todavia, a deficiência de registros e as dificuldades na identificação das causas originárias prejudicam a revelação do real quadro epidemiológico nesse particular. 0 sub-registro mascara o grave quadro percebido pelos entrevistados.

Os serviços participantes da pesquisa mantêm contato (encaminhando e recebendo paci- entes) com outros órgãos que têm interfaces no atendimento dos idosos vítimas de violências e acidentes, especial mente Secretaria Municipal de Saúde, Polícia, Fundação de Ação Social, ConseIho do Idoso, M inistério Público, porém se ressentem de melhor sistematização funcional e padronização de procedimentos.

À exceção de al guns aspectos como transporte, leitos em UTI, capacitação de recursos humanos e instalações físicas adaptadas ao atendimento ao idoso, de modo geral a estrutura dos serviços foi considerada suficiente e adequada, mas a pressão da demanda crescente dos pacientes idosos implicará também o comprometimento de outras áreas, agravando os problemas da assistência ${ }^{13}$.

As notificações dos casos de acidentes e violências contra idosos não seguem uma padronização. Em muitas situações, por não ser compulsória, a decisão da notificação, bem como os mecanismos e órgãos para os quais a comunicação será feita, estão sujeitos ao critério pessoal do profissional que prestou 0 atendimento ao idoso. 0 sistema de registros dos casos suspeitos ou confirmados de idosos vitimizados é frágil e não segue um padrão em nível municipal.

Os profissionais que atendem diretamente 0 idoso vitimizado, segundo os serviços participantes, não se apresentam capacitados para identificar os casos de violência, bem como para prosseguir com os encaminhamentos que esse tipo de situação requer visando à situação futura e ao melhor atendimento do idoso. Existem poucos profissionais com formação nas áreas de geriatria e gerontologia atuando nos serviços pesquisados. São pontuais, escassas, as ações de ordem preventiva, realizadas pelos serviços, nos diferentes níveis, com relação a casos de acidentes e violência contra idosos.

A família constitui um elemento de suporte muito importante para os serviços de saúde, na busca de um atendimento melhor e integral ao idoso ${ }^{14}$. A participação da família em algumas situações é fundamental para a recuperação do idoso vitimizado, por isso muitos serviços afirmaram estabelecer contatos com familiares dos idosos.

Como em outras localidades ${ }^{15}$, não ficou caracterizado o estabelecimento de uma rede de proteção eatendimento ao idoso, a qual seja consistente, eficientee resolutiva, ainda que el ementos valiosos para a formatação e o funcionamento de um sistema em rede já estejam presentes/disponíveis em Curitiba. A iniciativa de se estabelecer uma Unidade de Saúde especializada no aten- 
dimento ao idoso, no distrito com maior percentual de idosos, no município de Curitiba, re vela preocupação governamental em responder mais adequadamente às demandas específicas dessa população e é um exemplo de boa prática em saúde do idoso. A Central de Resgate Social (SOS Idoso) apresenta-se como um ponto de articulação intersetorial importante para dar resposta emergencial aos casos de denúncia de idosos vítimas de violências.

A rede de assistência ao idoso portador de transtorno mental e drogadição está em fase de reorganização etem potencial para 0 atendimento de idosos vitimizados, embora atualmente atenda basicamente o público adulto. Por se tratar de situações que extrapolam a esfera da saúde, tendo interfaces com outros segmentos da sociedade, os casos de idosos vítimas de acidentes e violência devem ser tratados por uma equipemultiprofissional, com o envolvimento desetores (saúde, justiça, assistência social, polícia e organizações comunitárias, entre outros) que, operando em rede, possibilitem suporte mais adequado e integral às necessidades dessas pessoas. Serviços como os desempenhados pela Unidade de Atenção ao Idoso Ouvidor Pardinho e Central de Resgate Social, prestadores desse tipo de atenção e assistência integradas, devem ser difundidos e ampliados.

\section{Conclusões}

0 tema dos acidentes e violência contra idosos tem tratamento ainda incipiente nas ações desenvolvidas pelos serviços pesquisados. Não há um plano específico de atendimento ao idoso vitimizado, nem definição defluxos de aten dimento. Faltam protocolos com abordagem preventiva e há deficiência nos registros de casos.

A maioria dos serviços não desenvolve atendimentos específicos, direcionados às demandas particulares dos indivíduos idosos, ou seja: em geral, osidosos recebem atendimento como qual- quer pessoa de outra faixa etária adulta. A experiência e a percepção de muitos entrevistados revelam sérias dificuldades de obtenção de leitos hospitalares, principalmente de UTI, para encaminhamento ou transferência de pacientes idosos.

Entretanto, há sinais positivos de que o problema já começa a constar das agendas governamentais, revelados por meio da organização de uma UBS especializada na atenção à saúde dos idosos numa perspectiva multidisciplinar e intersetorial, e pelo serviço prestado pela Central de Resgate Social, que inclui o SOSI doso. Procura-se, cada vez mais, integrar áreas afins de modo a consolidar uma rede de proteção social ao idoso vítima deacidentes eviolência, bem como proporcionar adequado suporte a sua família.

Para o enfrentamento das questões relativas aos acidentes eviolências contra idosos em Curitiba, deve-se ainda considerar a necessidade de organização de dados, por meio do estabelecimento de padrões de registros; fluxos entre as instituições que compõem o sistema; capacitação dos profissionais que atuam tanto no nível estratégico e de planejamento quanto no operacional, pois a partir de um sistema seguro eintegrado de registros que melhore a qualidade da informação poder-se-á gerar um padrão virtuoso de desenvolvimento de programas de preven ção, assistência e reabilitação aos idosos vitimizados.

A capacitação deprofissionais queatuam nos serviços de saúde e outros que se encontram relacionados à temática do idoso vitimizado é premente para identificação, atuação, encaminhamento e acompanhamento dos casos de acidentes eviolência. Tais preocupações devem ser assimiladas também pela academia, com ações consequentes, como adaptação de currículos, oferta de cursos especiais, interação comunitária e intersetorial nesse campo.

A sociedade deve ser esclarecida dos fatores condicionantes dos acidentes eviolências queafetam a população idosa e estimulada a combater posturas e atitudes discriminatórias e negligentes com relação aos idosos. 


\section{Colaboradores}

ALSF de M elo participou da coleta e análise dos dados e redação do artigo. SJ M oysés participou da coordenação local do estudo, análise dos dados e redação do artigo.

\section{Referências}

1. M inayo MCS. Violência contra idosos: relevância para um velho problema. Cad Saude Publica 2003; 19(3):783-791.

2. Espindola $C R$, Blay SL. Prevalência de maus-tratos na terceira idade: revisão sistemática. Rev Saude Publica 2007; 41(2):301-306.

3. Gawryszewski VP et al. Mortes e internações por causas externas entre os idosos no Brasil: o desafio de integrar a saúde coletiva e atenção individual. Rev Assoc M ed Bras 2004; 50(1):97-103.

4. Souza JAV de et al. Violência contra os idosos: análise documental. Rev Bras Enferm 2007; 60(3):268272.

5. Garrido R et al. O Brasil está envelhecendo: boas e más notícias por uma perspectiva epidemiológica. Rev Bras Psiquiatr 2002; 24(Supl. 1):3-6.

6. Deslandes SF, Souza ER, Minayo MCS, Costa CRBSF,Krempel M, Cavalcanti ML,Lima MLC, Moysés SJ, Leal ML, Carmo CN. Caracterização diagnóstica dos serviços que atendem vítimas de acidentes e violências em cinco capitais brasileiras. Cien Saude Colet 2006; 11(Supl.):1279-1290.

7. M inayo MCS, Assis SG, Souza ER. Avaliação por triangulação de métodos: abordagem de programas sociais. Rio de Janeiro: Editora Fiocruz; 2005.

8. Prefeitura de Curitiba. Secretaria de Saúde. Relatório anual de gestão, 2008. Curitiba; 2008.

9. Prefeitura de Curitiba. Secretaria de Saúde. Coordenação do serviço médico de urgência da SS. Relatório. Curitiba; 2007.

10. Sales FM, Santos I. Perfil de idosos hospitalizados e nível de dependência de cuidados de enfermagem: identificação de necessidades. Texto Contexto Enferm 2007; 16(3):495-502.

11. Ribeiro AP, Souza ER, Atie S, Souza AC, Schilithz AO. A influência das quedas na qualidade de vida de idosos. Cien Saude Colet 2008; 13(4):1265-1273.

12. Rodrigues MAP, Facchine RXP, Tomasi $E$, Thumé E, Silveira DS, Siqueira FV, Paniz VM VP. Uso de serviços básicos de saúde por idosos portadores de condições crônicas, Brasil. Rev Saúde Pública 2009; 43(4):604-612.

13. Veras R. Envelhecimento populacional contemporâneo: demandas, desafios e inovações. Rev Saúde Pública 2009; 43(3):548-554.

14. Leite MT, Battisti IDE, Berlezi EM, Scheuer AI. Idosos residentes no meio urbano e sua rede de suporte familiar e social. Texto Contexto Enferm 2008; 17(2):250-257.

15. Souza ER, Ribeiro AP, Atie $S$, Souza AC, Marques CC. Rede de proteção aos idosos do Rio de Janeiro: um direito a ser conquistado. Cien Saude Colet 2008; 13(4):1153-1163.

Artigo apresentado em 17/08/2009

Aprovado em 23/02/2010

Versão final apresentada em 21/04/2010 